\title{
MAXILLARY SINUS LIFT TO ENABLE ONE STAGE IMPLANT PLACEMENT USING NANOBONE AND PRF WITH OR WITHOUT SIMVASTATIN
}

\author{
Omar Hassan Soliman*
}

\begin{abstract}
Objective: Aim of this study was to evaluate the effect of using Nanobone and PRF with or without simvastatin on sinus lift and one stage implant placement.

Material \& Methods: 20 patients need sinus lift for implant placement in atrophied posterior maxilla were divided in two groups (group I: maxillary sinus lift made by using synthetic bone substitute (NanoBone) and PRF Without simvastatin, while in group II using NanoBone and PRF with simvastatin.
\end{abstract}

Results: Six months after surgery the mean of bone height gain in group I was $11.349 \mathrm{~mm}$ and the mean bone density was 297.8 Hounsfield units, while in group II the new bone height was $11.889 \mathrm{~mm}$ and the mean bone density was 314.3 Hounsfield units. During and after surgery there were no major complication and no implant failure. For endo sinus bone gain results were statistically significant in favour of group II $(\mathrm{P}<0.05)$.

Conclusion: Both regenerative approaches showed significant improvements in clinical and radiographic results. However, adding simvastatin in combination with Nanobone and PRF showed better bone gain at 6 months in maxillary sinus lift and implant placement.

Clinical Relevance: For maxillary sinus lift the additional use of simvastatin to Nanobone and PRF offers a clinical benefit in terms of bone height gain and bone density.

KEYWORDS: bone substitutes, sinus lift, dental implant, simvastatin.

\section{INTRODUCTION}

Dental implant is a standard treatment to replace missing teeth and support dental prosthesis for obtaining proper aesthetic and functions.
Rehabilitation of the atrophied posterior maxilla is not an easy procedure Esposito $M$ et al. 2014. The first trial for maxillary sinus augmentation was in 1980 and this technique has been studied over the years. Lateral window approach technique has been

* Lecturer, Periodontology, Oral Medicine and Oral Diagnosis Department, Faculty of Dentistry South Valley University 
used commonly for maxillary sinus augmentation Moon JW et al. 2015. Maxillary sinus lift is a surgical technique done to increase bone height in posterior maxilla by repositioning the maxillary sinus floor in upward direction to create adequate bone height suitable for placing dental implants $\boldsymbol{A l}$ -

\section{Dajani M 2016.}

Autogenous bone is the gold standard for ridge augmentations Xavier SP et al. 2015 but amount of the available autogenous bone are limited, creating morbidity to the donor site, and the time of the surgical operation is longer Ahmet S et al 2016.

Nanotechnology has been used in periodontal tissue regeneration. Several studies demonstrated the significant effect of nanoscale geometry and topography on the cell differentiation and regeneration Bartold PM et al. 2015. Nanobone (Artoss co, Germany) consisted of synthetic nano crystalline hydroxyapatite and silica fabricated in a sol/gel process. Nanobone increases osteoblasts proliferation better than deproteinized bovine bone mineral (DBBM) Liu, Q. et. al.2011. Study showed that the inflammatory reaction is less in nano bone graft than Beta-Tricalcium phosphate graft Ghanaati et al. 2013 b.

Heinemann, F et al. 2009 studies showed good results in clinical long term of implant insertions and simultaneous maxillary sinus augmentation by using Nanobone which provide reliable and dimensionally stable bone substitute material Kruse, A et al. 2011.

Strategies for accelerating bone healing include using of platelet rich plasma (PRF) which is highly concentration of the patient platelets that is rich in various groups of growth factors such as platelet derived growth factor, transforming growth factor beta, vascular endothelial growth factor, insulin growth factor 1 and others Marx RE. 2001. PRP considered as a complement to autogenous bone graft and osteoconductive graft material which improve bone healing Khairy NM et. al 2013.
Studies showed good results about the effect of using PRF when combined with bone substitute for maxillary sinus augmentation Taschieri $S$, et al 2015.

Statins are a drug used for the treatment of hypercholestrolemia by inhibiting 3-Hydroxy 3-Methylglutaryl coenzyme A reductase and convert it to mevalonate and decrease hepatic synthesis of cholesterol Horiuchi $\mathbf{N}$ et. al 2006. Statin derivate mevalonate and suppress the expression of the receptor for activation of nuclear factor kappa B ligand and activation of nuclear factor kappa $B$ which inhibits osteoclast differentiations and induces osteoclast apoptosis Mo H et al 2012. Mundy et al. 1999 studies showed that using of statins give rise to the so called pleiotropic effects by increasing the expression of bone morphogenetic proteins which stimulate the differentiation of osteoblast and increase its activity. Studies concluded that statin have an anabolic effect on bone Ho, M.L. et al 2009. Animal studies showed that when statin applied locally give good bone regeneration Goes $P$ et.al. 2006 and enhance new bone formation and bone to implant contact Fang, W et.al.2015.

Therefore, the aim of the present study was evaluating the clinical and radiographic effect of simvastatin when added to nano bone and PRF for maxillary sinus lift and simultaneous implant placement.

\section{MATERIALS AND METHODS}

The study designed for evaluating bone substitute effect; Nanobone (Artoss GmbH, Rostock, Germany) and PRF (group I, control group) compared to the same bone substitute and PRF with simvastatin (Corvast $80 \mathrm{mg}$, Egyphar, Egypt) (group II, test group) for maxillary sinus lift and placement of implants (Impla implant system, Scheutz dental group). This study included 20 patients, all of them required sinus lift and conducted in the Department of Periodontology, Oral Medicine 
and Oral Diagnosis, Faculty of dentistry, South Vally university.

Exclusion criteria were as follows: The exclusion criteria were bleeding index and plaque index of $>25 \%$, smoker patient, pregnant women, patients with active periodontal disease or periapical lesions, pathologic lesions of maxillary sinus, and patients with systemic diseases.

Inclusion criteria: All patients have $4 \mathrm{~mm}$ bone height in the posterior maxilla, the alveolar bone ridge was wide enough to enable implant placement during sinus lift and no maxillary sinus pathological lesion. Cone beam computed tomography done preoperative and 6 months postoperative and used to evaluate bone height gain and bone density of new formed bone.

\section{Surgical phase}

Lateral window technique with simultaneous implants insertion used. Before the surgical procedure, patient preparation was done by antibiotics (Augmentin 1gm, GlaxoSmithKline co). One gram given to the patient one day before the operation and continue for seven days. $0.2 \%$ chlorhexidine gluconate mouth wash used for all patients for 2 minutes before surgery.

Surgery was done under local anaesthesia and using piezosurgery (Piezosurgery, Acteon Co) to minimise surgical trauma and complications. Midcrestal mucosal incision done with releasing vestibular incision anteriorly and posteriorly to osteotomy site. Full thickness flap reflected to expose the lateral maxillary wall. Bony window created with the piezoelectric instrument so that the schneiderian membrane preserved and became visible. The sinus membrane elevated and fractured bone section kept attached to the astral lining and no attempt was made to separate it. Implants site prepared and the sinus cavity filled by Nanobone and PRF without simvastatin in Group I, while in Group II the sinus cavity filled with Nanobone and PRF with simvastatin, then implants inserted .
According to Choukroun's protocol to prepare PRF, patient blood samples harvested immediately before the surgery. PRF clots prepared and mixed with Nanobone in (group I) while in (group II), mixed with Nanobone and simvastatin. Part of PRF used as a membrane to cover wound before the closure Choukroun, A. et al. 2006.

After surgery patients were followed up and evaluated: seven days, one month, six months postoperatively. Patient clinically evaluated regarding any postoperative complication like pain, oedema, wound dehiscence, graft or implant failure.

Panoramic $\mathrm{x}$ ray taken after the surgery and CBCT was performed six month after surgery to evaluate the bone formation and bone density of new formed bone, and prosthetic rehabilitation started.

\section{Prosthetic restoration}

After 6 months of sinus lift and simultaneous placement of the implants, the cover screw of each implant was removed and a gingival former was placed. Gingival former removed after seven days. By closed tray technique, impression was taken. At $15 \mathrm{Ncm}$, the abutment tightened using a torque driver. PFM (porcelain fused to metal) crowns fabricated and cemented with zinc phosphate cement.

\section{RESULTS}

After six-months follow up period for 20 partially edentulous patients who treated for sinus floor augmentation and one stage implant placement by using Nanobone and RPF without simvastatin in Group I, while in group II Nanobone and RPF with simvastatin has been used. The results of our study showed $100 \%$ success rate. No intraoperative clinical complication such as sinus membrane perforation nor postoperative complication such as maxillary sinusitis or pain. Healing of the surgical site took place without any complication or infection, but at the second day after surgery, one patient reported minor discomfort and was managed by analgesics. 


\section{Radiological Results}

By comparing the finding of CBCT preoperative ad 6 months after surgery, the end sinus bone height gain is measured by subtraction the preoperative residual bone height from the postoperative new bone height. The mean vertical bone gain height 6 months after surgery was $11.349 \mathrm{~mm}$ in group I and $11.889 \mathrm{~mm}$ in group II.

The bone density in the grafted areas were evaluated in both groups. The residual bone height $(\mathrm{RBH})$ measurement from the preoperative CBCT images showed the vertical distance from the cortex bone under the floor of the maxillary sinus to the alveolar bone crest. This difference in sinus augmentation height did reach statistical significance. Comparison of radiographic findings, the mean of new formed bone density was 297.8 Hounsfield in group I while it was 314.3 Hounsfield in group II. The difference in the density of new formed between the two groups was statically significance for group II $(\mathrm{P}<0.05)$. This results showed that the density of new formed bone in group II was denser than the density of new formed bone in group I.

TABLE (1) Showing radiographic CBCT results for bone height and bone density.

\begin{tabular}{|c|c|c|c|c|}
\hline Patient number & $\begin{array}{c}\text { New bone Density } \\
\text { (hounsfield units) } \\
\text { Group I }\end{array}$ & $\begin{array}{c}\text { New bone Density } \\
\text { (hounsfield units) } \\
\text { Group II }\end{array}$ & $\begin{array}{c}\text { Bone Height }(\mathrm{mm}) \\
\text { Group I }\end{array}$ & $\begin{array}{c}\text { Bone Height (mm) } \\
\text { Group II }\end{array}$ \\
\hline 1 & 295 & 293 & 11.50 & 11.95 \\
\hline 2 & 278 & 325 & 11.50 & 13.00 \\
\hline 3 & 260 & 339 & 13.00 & 12.50 \\
\hline 4 & 315 & 242 & 11.75 & 11.80 \\
\hline 5 & 301 & 350 & 11.89 & 11.90 \\
\hline 6 & 332 & 299 & 12.10 & 12.50 \\
\hline 7 & 298 & 327 & 11.4 & 11.7 \\
\hline 8 & 287 & 289 & 9.55 & 10.69 \\
\hline 9 & 304 & 323 & 10.3 & 11.10 \\
\hline 10 & 308 & 356 & 10.5 & 11.78 \\
\hline $\begin{array}{c}\text { Mean of differences } \\
\text { (IQR) }\end{array}$ & 297.80 & 314.3 & 11.349 & 11.889 \\
\hline$P$ value & 0.039 & & 0.192 & \\
\hline
\end{tabular}




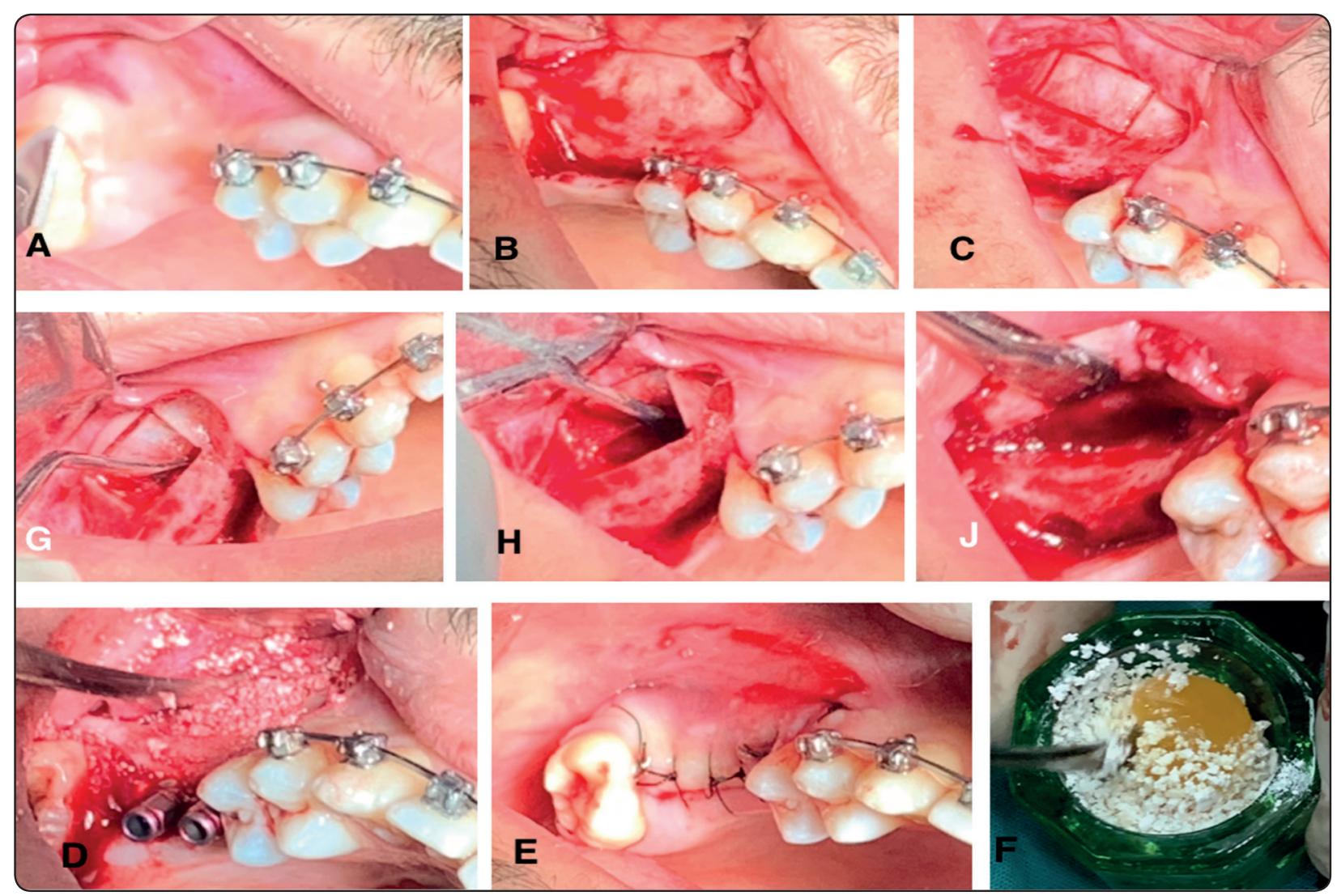

Fig. (1) Fig.1: Showing surgical sinus operation lift and one stage implant placement: A) Maxillary posterior ridge before sinus lift. B) Flap design. C,D and E): Bony window created with the piezoelectric instrument. F) Preparation of implant site. G) Placement of Nanobone \& PRF with simvastatine. H) Suturing. J) Mixing of Nanobone, PRF and simvastatin.

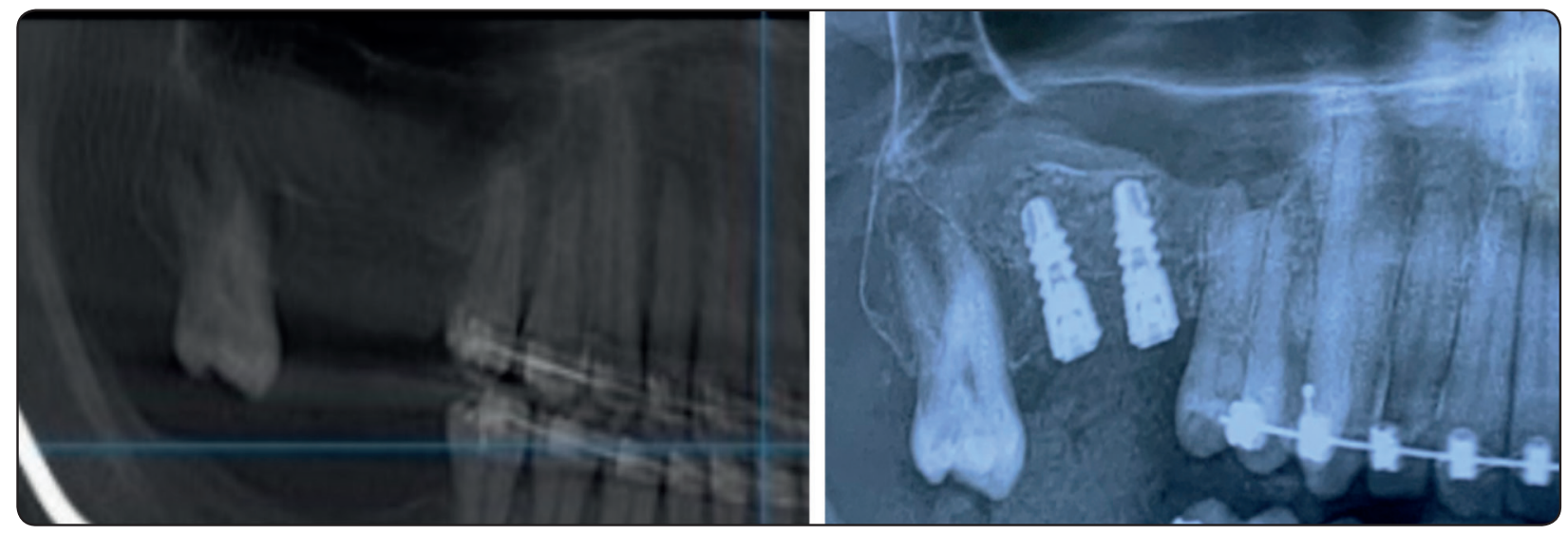

Fig. (2) Showing preoperative \& postoperative panoramic x ray. 


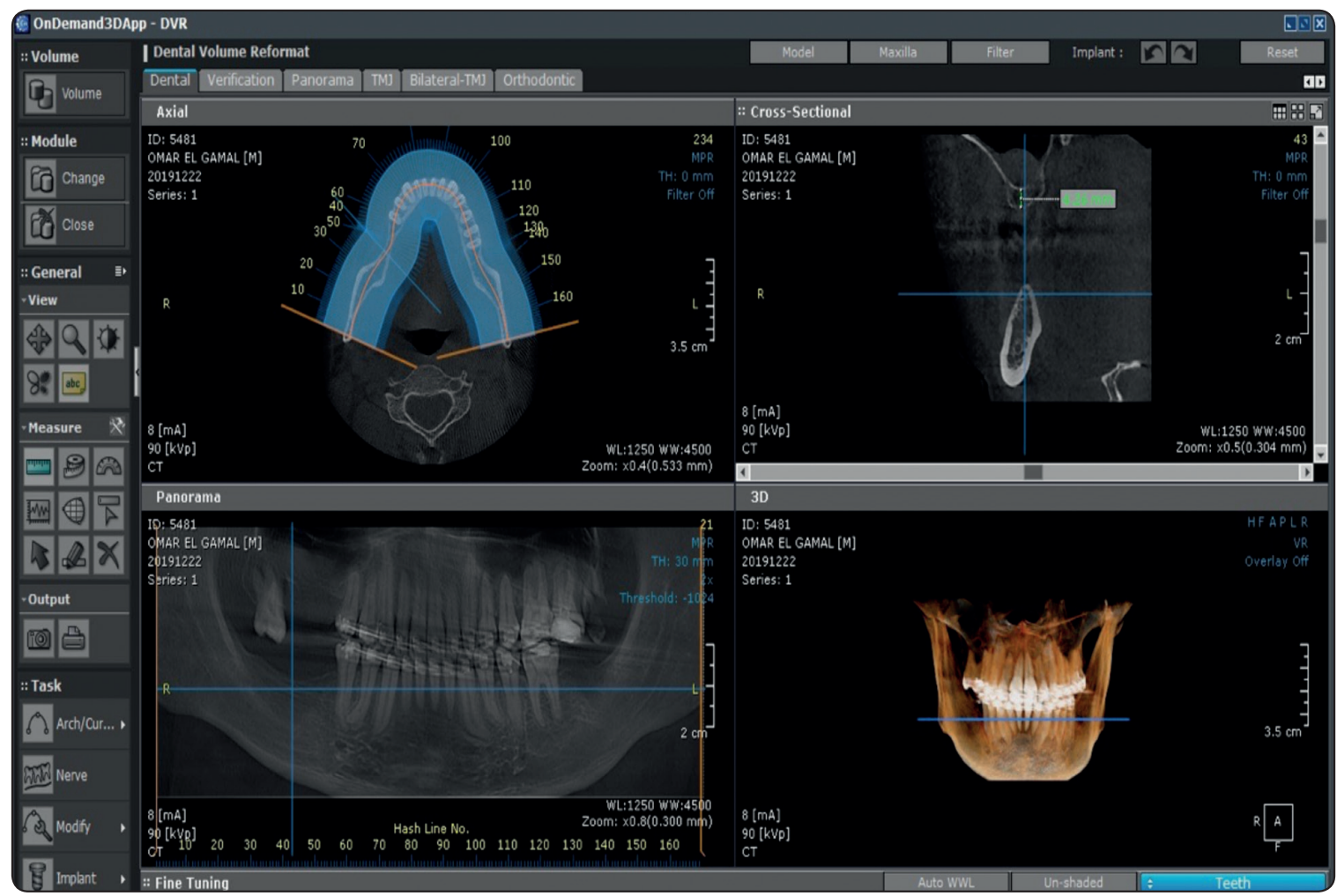

Fig.3: Showing preoperative CBCT.

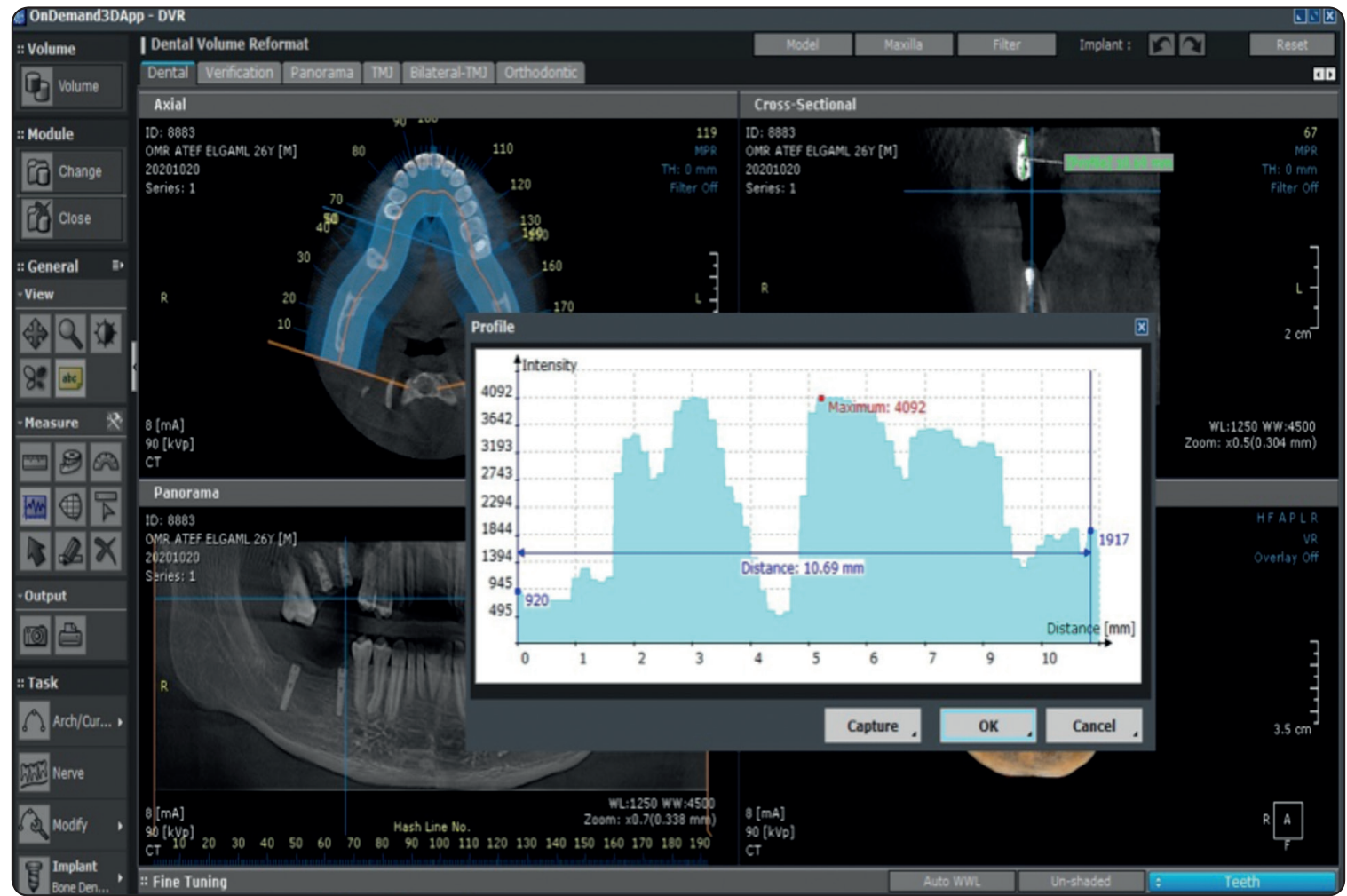

Fig. 4: Showing 6 months postoperative CBCT, measuring the height of endo sinus bone gain. 


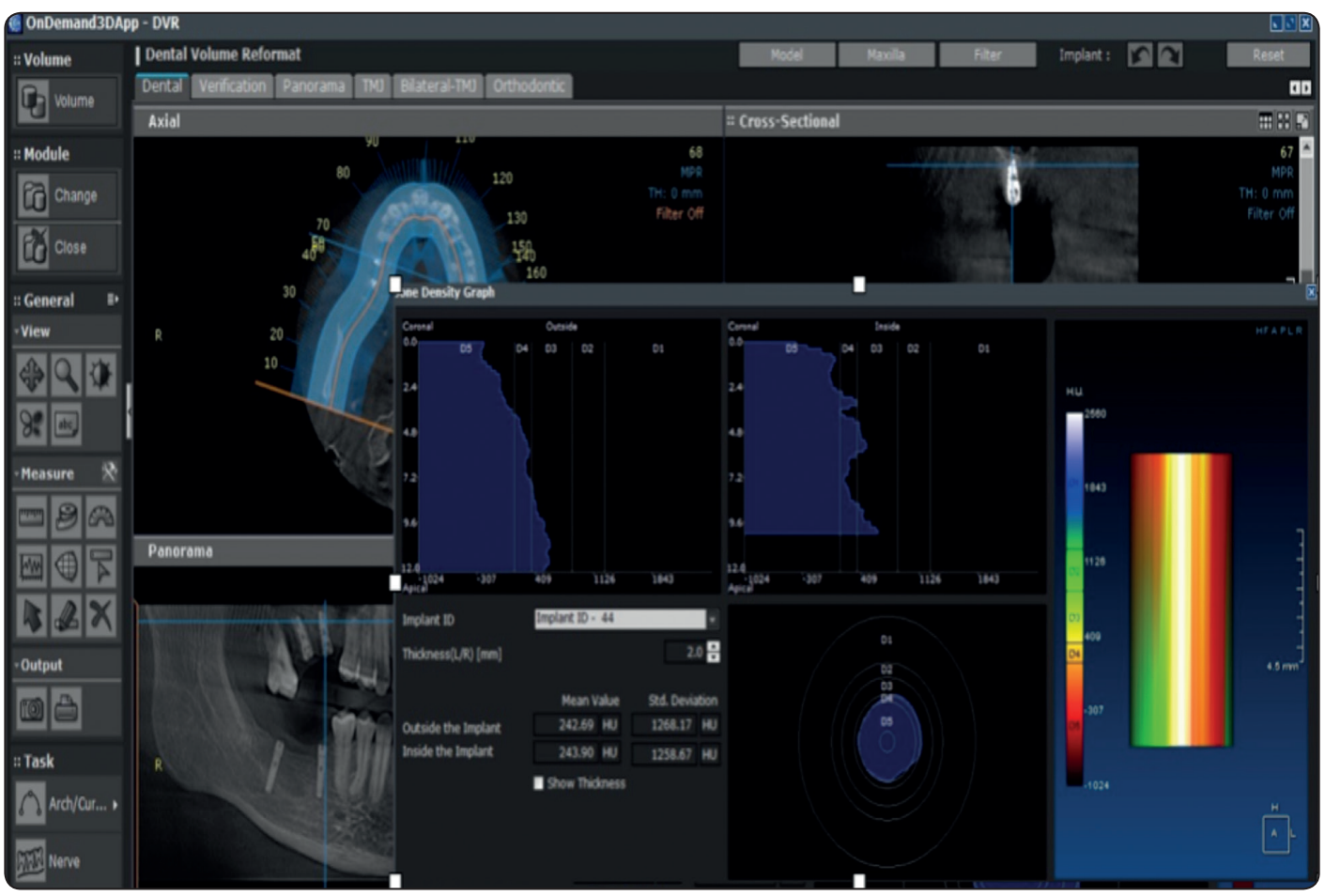

Fig. 5: Showing 6 months postoperative CBCT, measuring the height of endo sinus bone density.

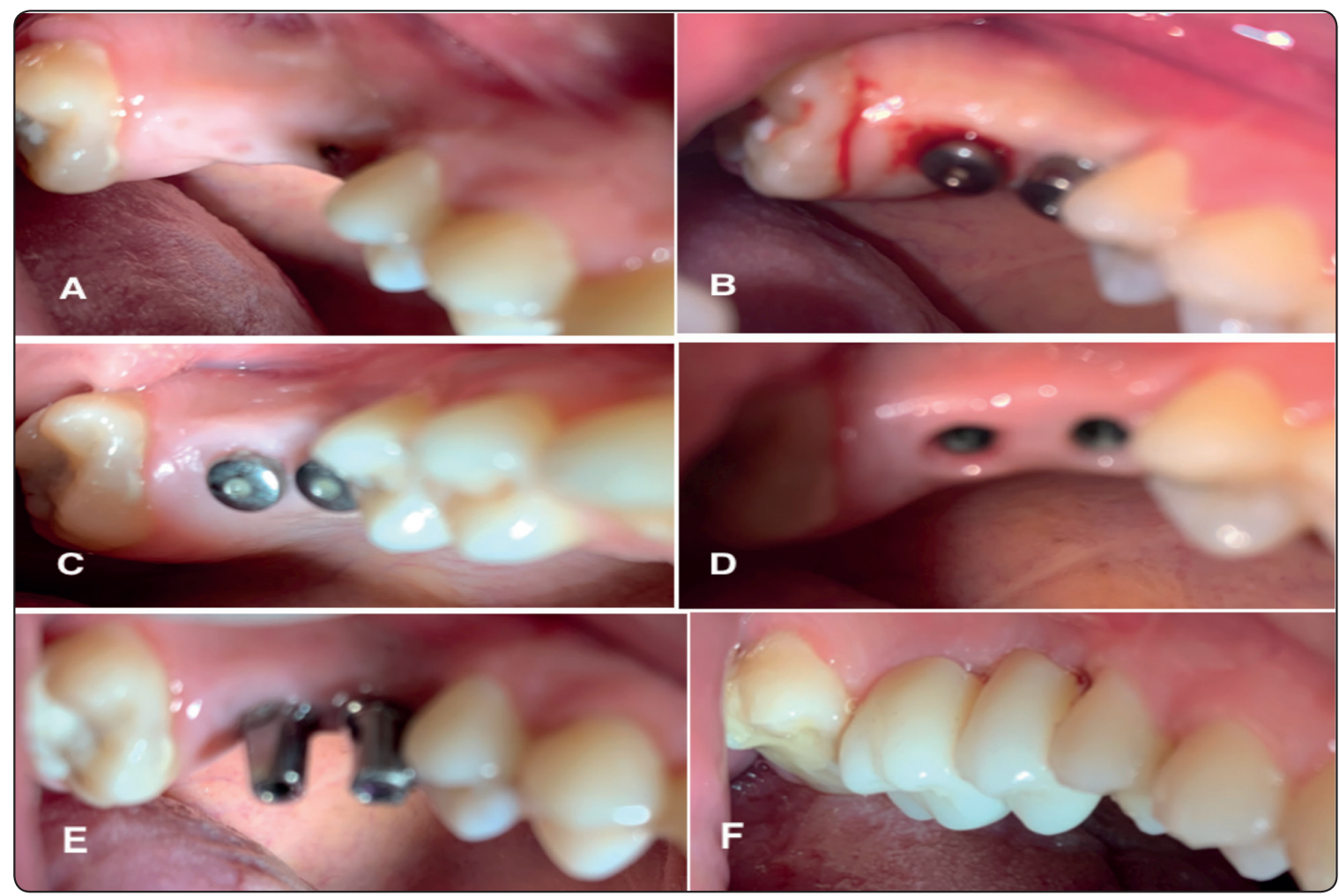

Fig. (6) Prosthetic Phase. A) Photo showing ridge 6 months after sinus lift and implant placement. B) Photo showing placement of gingival former. C) Photo showing of gingiva and gingival former after one week. D) Photo showing gingiva after removal of gingival former after one week. E) Photo showing placement of abutments. F) Photo showing cementation of the prosthetic crowns. 


\section{DISCUSSION}

Maxillary sinus lift is a well accepted procedure for increasing bone volume in the posterior maxilla. Three options are available for maxillary sinus lift and placement of the implant; two stage lateral sinus lift, one stage lateral sinus lift with simultaneous implant placement, and one stage crestal approach with simultaneous implant placement, each of this options has advantages and disadvantages. Two stage lateral sinus lift indicated when the available bone height is less than $3 \mathrm{~mm}$, one stage lateral sinus lift indicated when the available bone height 4 $\mathrm{mm}$ and one stage crestal approach indicated when the available bone height is above $4 \mathrm{~mm}$ Kendrick DE 2016. In this study all included patients have $4 \mathrm{~mm}$ bone height in the posterior maxilla and the alveolar bone ridge was wide enough to enable implant placement during sinus lift.

Lateral approach technique for sinus lift is invasive and associated with more complications than crestal one stage approach Bechara et al.2016. In this study, using piezoelectric device for lateral window preparation and membrane separation decreased the intraoperative complications. This result was correlated with the results of $\boldsymbol{I}$. Woo $\& \boldsymbol{B}$. T. Le 2004 and the histomorphological studies of Pavlikova G et al. 2011. The piezoelectric surgery increases the concentration of bone morphogenic protein, transforming growth factor beta 2 , tumor necrosis factor and decreases proinflammatory cytokine in the bone. Piezosurgery acts only on mineralized tissue and inactives on soft tissue, hence soft tissue damage is absent S.S. Wallace 2012.

This study was designed to compare the efficacy of combining simvastatin to Nanobone graft and PRF in maxillary sinus lift based on the new bone height gain and the density of new formed bone. Nanobone graft is well documented and have applications in oral surgery, as it promotes bone regeneration because it is biocompatible and osteoconductive. Combining simvastatin to bone substitute has been less investigated. PRF is an autologous fibrin matrix. It is used to enhance bone regeneration as it stimulates osteoblast proliferation C.H. Tsai 2009. Animal studies showed that, PRF influenced the early bone healing and was beneficial for less vascularized areas, such as maxillary sinus Gerard, E et al. 2006 and Miron R. J. et al 2010. The radiological analysis of new formed endo sinus bone density was conducted on the study of Consolo U. 2007 and Olgun E et al. 2018 which reported that, the bone density of PRF group was better than the bone density of control group.

This study evaluated 40 implants placed in 20 patients, the success rates for sinus lift and implants placement were $100 \%$. The success of maxillary sinus lift determined by the amount of new formed bone in the augmented area Loin J et al. 2019. The results of this study showed that, an average vertical bone gain in group II was $11.889 \mathrm{~mm}$, while in group I was $11.349 \mathrm{~mm}$. This result was correlated with the results reported in other studies Kiliç et al.2016, Cucchi, $A$ et al. 2017 and Fouad, W et al. 2018 but differed significantly from the data reported by Meyer et al. 2009. They observed a mean height bone gain of $16 \mathrm{~mm}$, but in their study they used beta tricalcium phosphate and PRF for maxillary sinus lift. It should be taken into account that during the surgery bone graft was placed as much as necessary until all the implants were covered and that could be a plausible reason for longer implants to have obtained greater regeneration. These results was correlated with the results reported in the study of Tanaka, K et al. 2019.

The results of this study showed that, the mean of new formed bone density was 297.8 Hounsfield units in group I, while in group II the mean of new formed bone density was 314.3 Hounsfield units. This result was correlated with the results reported in other studies Khairy $N$ et al 2013, Kiliç et al. 2016, Cucchi, A et al. 2017 and Fouad Wet al. 2018. 


\section{CONCLUSION}

The results of this study showed that, the new bone height gain and new formed bone density in group II was better than the group I. The results of this study confirms that, combining simvastatin with Nanobone graft \& PRF has a more positive impact on increasing the bone gain and bone density when compared with Nanobone and PRF alone.

\section{REFERENCES}

- Aa H, Sbm P, Kohal RJ, Gubik S, Strohl C, Stampf S, Alexander A, Maria B. Effect of two different healing times on the mineralization of newly formed bone using a bovine bone substitute in sinus floor augmentation: a randomized, controlled, clinical and histological investigation; 2015. p. 1052.

- Ahmet S, Alper Gultekin B, Karabuda ZC, Olgac V. Two composite bone graft substitutes for maxillary sinus floor augmentation: histological, histomorphometric, and radiographic analyses. Implant Dent. 2016;25(3): 313-21.

- Al. Dajani M Al: Recent trends in sinus lift surgery and their clinical implications. Clin Implant Dent Relat Res: 18 (1) : $204 / 12,2016$.

- Annibali S, Iezzi G, Sfasciotti GL, et al: Histological and histomorphometric human results of HA- Beta-TCP compared to three different biomaterials in maxillary sinus augmentation at 6 months: a preliminary report. Biomed Res Int, 2015.

- Buser D, Weber HP, Lang NP. Tissue integration of nonsubmerged implants. 1-year results of a prospective study with 100 ITI hollow-cylinder and hollow-screw implants. Clin Oral Implants Res. 1(1):33-40, 1990.

- Bartold PM, Gronthos S, Ivanovski S, Fisher A, Hutmacher DW. 2016. Tissue engineered periodontal products. J Periodontal Res. 51(1):1-15.

- Calasans-Maia MD, Mourão CF, Alves AT, Sartoretto SC, de Uzeda MJ, Granjeiro JM. Maxillary sinus augmentation with a new xenograft: a randomized controlled clinical trial. Clin Implant Dent Relat Res. 2015; 17(Suppl 2):e586-93.

- C.H. Tsai, S.Y. Shen, J.H. Zhao, and Y.C. Chang, "Platelet- rich fibrin modulates cell proliferation of human periodontally related cells in vitro," Journal of Dental Sciences, vol. 4, no. 3, pp. 130-135, 2009.
- Choukroun, A. Diss, A. Simonpieri et al., "Platelet-rich fibrin (PRF): a second-generation platelet concentrate. Part V: histo- logic evaluations of PRF effects on bone allograft maturation in sinus lift," Oral Surgery, Oral Medicine, Oral Pathology, Oral Radiology, and Endodontology, vol. 101, no. 3, pp. 299-303, 2006.

- Consolo U., D. Zaffe, C. Bertoldi, and G. Ceccherelli, "Platelet- rich plasma activity on maxillary sinus floor augmentation by autologous bone," Clinical Oral Implants Research, vol. 18, no. 2, pp. 252-262, 2007.

- Cucchi, A.; Vignudelli, E.; Napolitano, A.; Marchetti, C.; Corinaldesi, G. Evaluation of complication rates and vertical bone gain after guided bone regeneration with non-resorbable membranes versus titanium meshes and resorbable membranes. A randomized clinical trial. Clin. Implant. Dent. Relat. Res. 2017, 19, 821-832.

- D. E. Kendrick, "Vertical Implant Diagnosis and Treatment Planning for the Posterior Edentulous Maxilla Alveolar Ridge Augmentation, in Implant Dentistry: A Surgical Manual. Edit- ed by Len Tolstunov," in 1rst edition, pp. 135-143, John Wiley Sons, s Inc, 2016.

- $\quad$ Esposito M, Felice P, Worthington HV. Interventions for replacing missing teeth: augmentation procedures of the maxillary sinus. Cochrane Database Syst Rev. 2014; 5: CD008397.

- $\quad$ Fang, W.,Zhao, S.,He, F., Liu,L., Yang, G., 2015. Influence of simvastatin-loaded implants on osseointegration in an ovariectomized animal model. BioMed Res. Int. 2015, 831504 DOI: $10.1155 / 2015 / 831504$.

- $\quad$ Fouad, W.; Osman, A.; Atef, M.; Hakam, M. Guided maxillary sinus floor elevation using deproteinized bovine bone versus graftless Schneiderian membrane elevation with simultaneous implant placement: Randomized clinical trial. Clin. Implant. Dent. Relat. Res. 2018, 20, 424-433.

- Ghanaati, S., Udeabor, S.E., Barbeck, M., Willershausen, I., Kuenzel, O., Sader, R.A. \& Kirkpatrick, C.J. (2013b) Implantation of silicon dioxide-based nanocrystalline hydroxyapatite and pure phase beta-tricalciumphosphate bone substitute granules in caprine muscle tissue does not induce new bone formation. Head \& Face Medicine 9: 1.

- Gerard, E D.. R. Carlson, J. E. Gotcher, and M. Jacobs, "Effects of platelet-rich plasma on the healing of autologous bone grafted mandibular defects in dogs," Journal of Oral and Max- illofacial Surgery, vol. 64, no. 3, pp. 443-451, 2006. 
- Goes P, Lima NA, Rodrigues JAG, Benevides NMB, Brito GAC, Lima V (2016) Anti-inflammatory and antiresorptive effects of atorvastatin on alveolar bone loss in Wistar rats. BrazDent J Brazil 27:267-272.

- Heinemann, F., Mundt, T., Biffar, R., Gedrange, T. \& Goetz, W. (2009) A 3-year clinical and radiographic study of implants placed simultaneously with maxillary sinus floor augmentations using a new nanocrystalline hydroxyapatite. Journal of Physiology and Pharmacology 60(Suppl. 8): 91- 97.

- Horiuchi N, Maeda T. Statins and bone metabolism. Oral Dis. 2006;12:85-101.

- Ho, M.L., Chen, Y.H., Liao, H.J., Chen, C.H., Hung, S.H., Lee, M.J., Fu, Y.C., Wang, Y.H., Wang, G.J., Chang, J.K., 2009. Simvastatin increases osteoblasts and osteogenic proteins in ovariectomized rats. Eur. J. Clin. Invest. 39, 296-303.

- $\quad$ Khairy NM, Shendy EE, Askar NA, El-Rouby DH. Effect of platelet rich plasma on bone regeneration in maxillary sinus augmentation (randomized clinical trial). Int J Oral Maxillofacial Surg. 2013;42:249-55.

- Kiliç, S.C.; Güngörmüs, M. Cone Beam Computed Tomography Assessment of Maxillary Sinus Floor Augmentation Using Beta-Tricalcium Phosphate Alone or in Combination with Platelet-Rich Plasma: A Randomized Clinical Trial. Int. J. Oral Maxillofac. Implant. 2016, 31, 1367-1375.

- $\quad$ Kruse, A., Jung, R.E., Nicholls, F., Zwahlen, R.A., Hammerle, C.H. \& Weber, F.E. (2011) Bone regeneration in the presence of a synthetic hydroxyapatite/silica oxide-based and a xenogenichydroxyapatite-based bone substitute material. Clinical Oral Implants Research 22: 506- 511.

- $\quad$ Khairy N. M., E. E. Shendy, N. A. Askar, and D. H. ElRouby, "Effect of platelet rich plasma on bone regeneration in maxillary sinus augmentation (randomized clinical trial)," International Journal of Oral and Maxillofacial Surgery, vol. 42, no. 2, pp. 249-255, 2013.

- J. C. Carreñ o, A. Aguilar-Salvatierra, G. Gómez-Moreno et al., "Update of Surgical Techniques for Maxillary Sinus Augmentation: A Systematic Literature Review," Implant Dentistry, vol. 25, no. 6, pp. 839-844, 2016.

- Lee JH, Kim JH, Jeon JH. Bone regeneration of macropore octacalcium phosphate-coated deproteinized bovine bone materials in sinus augmentation: a prospective pilot study. Implant Dent. 2015;24(3):275-80.
- $\quad$ Loin, J.; Kün-Darbois, J.D.; Guillaume, B.; Badja, S.; Libouban, H.; Chappard, D. Maxillary sinus floor elevation using Beta-Tricalcium-Phosphate (beta-TCP) or natural bone: Same inflammatory response. J. Mater. Sci. Mater. Med. 2019, 30, 97.

- $\quad$ Liu, Q., Douglas, T., Zamponi, C., Becker, S.T., Sherry, E., Sivananthan, S., Warnke, F., Wiltfang, J. \& Warnke, P.H. (2011) Comparison of in vitro biocompatibility of NanoBone $((\mathrm{R}))$ and BioOss((R)) for human osteoblasts. Clinical Oral Implants Research 22: 1259- 1264.

- Olgun E., S. Y. Ozkan, H. T. Atmaca, M. Yalim, and M. K. Hendek, "Comparison of the clinical, radiographic, and histo- logical effects of titanium-prepared platelet rich fibrin to allo- graft materials in sinus-lifting procedures," Journal of Investigative and Clinical Dentistry, vol. 9, no. 4, article e12347, 2018

- Ozyuvaci, H.; Bilgiç, B.; Firatli, E. Radiologic and histomorphometric evaluation of maxillary sinus grafting with alloplastic graft materials. J. Periodontol. 2003, 74, 909-915.

- Marx RE. Platelet-rich plasma (PRP): what is PRP and what is not PRP? Implant Dentistry. 2001;10:225-8.

- Mo H, Yeganehjoo H, Shah A, Mo WK, Soelaiman IN, Shen C-L. Mevalonate suppressive dietary isoprenoids forbonehealth. J Nutr Biochem. 2012;23:1543-51.

- $\quad$ Miron R. J., C. J. Oates, A. Molenberg, M. Dard, and D. W. Hamilton, "The effect of enamel matrix proteins on the spreading, proliferation and differentiation of osteoblasts cultured on titanium surfaces," Biomaterials, vol. 31, no. 3, pp. 449-460, 2010.

- Mundy, G., Garrett, R., Harris, S., Chan, J., Chen, D., Rossini, G., Boyce, B., Zhao, M., Gutierrez, G., 1999. Stimulation of bone formation in vitro and in rodents by statins. Science 286, 1946-1949.

- Meyer, C.; Chatelain, B.; Benarroch, M.; Garnier, J.F.; Ricbourg, B.; Camponovo, T. Massive sinus-lift procedures with beta-tricalcium phosphate: Long-term results. Rev. Stomatol. Chir. Maxillo Faciale 2009, 110, 69.

- Moon JW, Sohn DS, Heo JU, Kim JS. Comparison of two kinds of bovine bone in maxillary sinus augmentation: a histomorphometric study. Implant Dent. 2015;24(1):19-24.

- Maniatopoulos C, Rodriguez A, Deporter DA, Melcher AH. An improved method for preparing histological sections of metallic implants. Int J Oral Maxillo Fac Implants. 1986;1:31-7. 
- Nyan M, Sato D, Oda M, Machida T, Kobayashi H, Nakamura T, Kasugai S. Bone formation with the combination ofsimvastatin and calcium sulfate in criticalsized rat calvarialdefect. J PharmacolSci. 2007;104:384-6.

- Nedir R, Bischof M, Vazquez L, Szmukler-Moncler S, Bernard JP. Osteotome sinus floor elevation without grafting material: a 1-year prospective pilot study with ITI implants. Clin Oral Implan Res. 2006;17(6):679-86.

- Raghoebar GM, Schortinghuis J, Liem RS, Ruben JL, van der Wal JE, Vissink A. Does platelet-rich plasma promote remodeling of autologous bone grafts used for augmentation of the maxillary sinus floor? Clin Oral Implants Res. 2005;16:349-56.

- Stein D, LeeY, Schmid MJ, Killpack B, Genrich MA, Narayana N, et al. Local simvastatin effects on mandibular bone growth and inflammation. J Periodontol. 2005;76:1861-70.

- Schwartz Z, Weesner T, van Dijk S, Cochran DL, Mellonig JT, Lohmann CH, Carnes DL, Goldstein M, Dean DD, Boyan BD. Ability of deproteinized cancellous bovine bone to induce new bone formation. J Periodontol. 2000;71(8):1258-69.

- $\quad$ Schulze-Späte, U.; Dietrich, T.; Kayal, R.A.; Hasturk, H.; Dobeck, J.; Skobe, Z.; Dibart, S. Analysis of bone formation after sinus augmentation using $\beta$-tricalcium phosphate. Compend. Contin. Educ. Dent. 2012, 33, 364-368.

- Silva HF, Abuna RPF, Lopes HB, Francischini MS, de Oliveira PT, Rosa AL, Beloti MM. Participation of extracellular signal-regulated kinases $1 / 2$ in osteoblast and adipocyte differentiation of mesenchymal stem cells grown on titanium surfaces. Eur J Oral Sci. 2017;125(5):355-60.

- $\quad$ S. Bechara, R. Kubilius, G. Veronesi, J. T. Pires, J. A. Shibli, and F. G. Mangano, "Short (6-mm) dental implants versus sinus floor elevation and placement of longer $(\geq 10$ $\mathrm{mm}$ ) dental implants: a randomized controlled trial with a 3-year follow-up," Clinical Oral Implants Research, 2016.

- $\quad$ S. S. Wallace, D. P. Tarnow, S. J. Froum et al., "Maxillary sinus elevation by lateral window approach: evolution of technology and technique," Journal of Evidence-Based Dental Practice, vol. 12, no. 3, pp. 161-171, 2012.

- Shakibaie, M.B. (2013) Comparison of the effectiveness of two different bone substitute materials for socket preservation after tooth extraction: A controlled clinical study. The International Journal of Periodontics \& Restorative Dentistry 33: 223-228.
- Panagiotou D, Özkan Karaca E, Dirikan Ipçi Ş, Çakar G, Olgaç V, Yılmaz S. Comparison of two different xenografts in bilateral sinus augmentation: radiographic and histologic findings. Quintessence Int. 2015;46(7):611-9.

- Parfitt AM, Drezner MK, Glorieux FH, Kanis JA, Malluche H, Meunier PJ, Ott SM, Rec-Ker RR. Bone histomorphometry: stan- dardization of nomenclature, symbols, and units. Report of the ASBMR Histomorphometry Nomenclature Committee. J Bone Mineral Res. 1987;2: 595-610.

- Pavlíková G, Foltán R, Horká M, Hanzelka T, Borunska H, Sedy J. Piezosurgery in oral and maxillofacial surgery. Int J Oral Maxillofac Surg. 2011;40:451-57.

- Tatum H Jr. Maxillary and sinus implant reconstructions. Dentistry Clinical North America. 1986;30:207-29.

- Tanaka H, Toyoshima T, Atsuta I, Ayukawa Y, Sasaki M, Matsushita Y, Hiraoka R, Koyano K, Nakamura S. Additional effects of platelet-rich fibrin on bone regeneration in sinus augmentation with deproteinized bovine bone mineral: preliminary results. Implant Dent. 2015.

- $\quad$ Tanaka, K.; Iezzi, G.; Piattelli, A.; Ferri, M.; Mesa, N.F.; Alccayhuaman, K.A.A.; Botticelli, D. Sinus Floor Elevation and Antrostomy Healing: A Histomorphometric Clinical Study in Humans. Implant Dent. 2019, 28, 537-542.

- Taschieri S, Testori T, Corbella S, Weinstein R, Francetti L, Giancamillo D, et al. Platelet-Rich Plasma and Deproteinized Bovine Bone Matrix in Maxillary Sinus Lift Surgery: A Split-Mouth Histomorphometric Evaluation. Implant Dentistry. 2015;24(5):592-7.

- Trombelli, L.; Franceschetti, G.; Stacchi, C.; Minenna, L.; Riccardi, O.; Di Raimondo, R.; Rizzi, A.; Farina, R. Minimally invasive transcrestal sinus floor elevation with deproteinized bovine bone or $\beta$-tricalcium phosphate: A multicenter, double-blind, randomized, controlled clinical trial. J. Clin. Periodontol. 2014, 41, 311-319.

- Woo and B. T. Le, "Maxillary sinus floor elevation: review of anatomy and two techniques," Implant Dentistry, vol. 13, no. 1, pp. 28-32, 2004.

- Xavier SP, Dias RR, Sehn FP, Kahn A, Chaushu L, Chaushu G. Maxillary sinus grafting with autograft vs. fresh frozen allograft: a split-mouth histomorphometric study. Clin Oral Implants Res. 2015;26(9):1080-5.

- Yang J, Xia T, Fang J, Shi B. Radiological changes associated with new bone formation following osteotome sinus floor elevation (OSFE): a retrospective study of 40 patients with 18-month follow-up. Med Sci Monit. 2018;24:4641-8. 